\title{
A vida e a teoria no tempo das redes e mídias sociais digitais
}

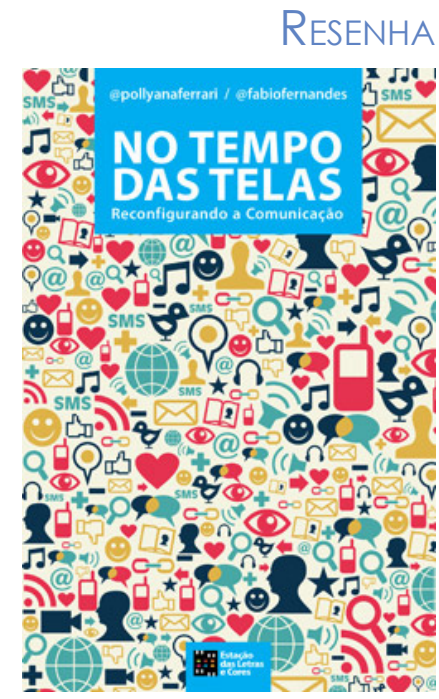

L Jefferson Jeanmonod de Azevedo Santana

Mestrando em Comunicação pela Universidade São Caetano do Sul (USCS) e graduado em Produção Publicitária pela Faculdade Carlos Drummond de Andrade. Docente no Centro Estadual de Educação Tecnológica Paula Souza (CEETEPS). E-mail: jefferson.santana21@etec.sp.gov.br

Mesclando ficção e ciência, No tempo das telas (2014), de Pollyana Ferrari e Fábio Fernandes, utiliza uma forma inovadora de organização visual ao abordar o tema das novas tecnologias da comunicação e informação no mundo pós-moderno. Os autores intercalam citações e pesquisas sobre teorias de comunicação na pós-modernidade com a ficção, por meio de histórias de pessoas que têm suas vidas e relacionamentos mediados por suas telas (computadores, tablets, celulares etc.).

Os autores utilizam-se de hibridismo de linguagens para desenvolver o tema de novas tecnologias da comunicação e informação no mundo pós-moderno. Em parte do texto identificam-se linguagens próprias do mundo acadêmico com citações diretas e indiretas, enquanto outros trechos do livro nos remetem à linguagem da internet com suas "hashtags", popularmente conhecidas como "jogo da velha" (\#), ou ainda o sinal de "arroba” (@) como parte da palavra, assim como é utilizado nas redes sociais. Encontramos trechos com histórias fictícias que contam como celulares, tablets e internet de banda larga estão na cultura e no cotidiano de personagens criados exclusivamente para o livro com os codinomes de "Alice e Pedro - a vegana e o nômade urbano"; da "Paula - a Garotade-Programa-com-uma-Câmera"; do "Joaquim - o Dinossauro Mandrake da Boneca Inflável"; "Ana Beatriz - a Blogueira-Capricho"; "Bruno - O Nerd-Instrospectivo"; "Regina e Samuca - o samurai que virou professor de história", do "Pita - Professor Rizomático". 
Quanto à estrutura, os capítulos começam com citações de obras literárias, poemas, músicas ou referências a obras de artes plásticas que têm relação com as profundas mudanças que as novas tecnologias da comunicação e informação empregam neste mundo globalizado, no que se referem às identidades, temporalidades, localidades e linguagens.

O layout do livro foi desenvolvido para deixar em evidência os diferentes tipos de gêneros textuais utilizados. É feita a distinção do texto acadêmico e do ficcional, sendo apresentados de várias formas: podem aparecer em gráficos, em desenhos específicos, medidas de margens diferentes, fontes tipográficas distintas e até mesmo no uso do travessão, indicando a fala das pessoas no diálogo.

Com essa diagramação não padronizada, os autores também distinguem quando o texto é de Pollyana Ferrari ou de Fábio Fernandes por meio de diferentes medidas de margens e estilos de fonte. Por exemplo, o que foi escrito por Ferrari é apresentado com tipografia parecida com a Times New Roman, com serifa, já os escritos de Fernandes aparecem em uma fonte semelhante à Arial, sem serifa.

O prólogo introduz o contexto das transformações percebidas e estudadas com o surgimento de novas tecnologias da comunicação e informação, principalmente com o advento da internet. Apresenta como a diagramação contribuirá para o entendimento da divisão entre os tipos de textos e os autores, os nomes dos personagens fictícios, que serão usados para exemplificar as relações entre pessoas e objetos que os conectam às suas redes sociais on-line e off-line por meio do ciberespaço e do espaço real.

Inicia-se, assim, a inserção da ideia de que o mundo real e o virtual muitas vezes se sobrepõem. Para os autores, a vida do ciberespaço é tentadora, e, muitas vezes, as pessoas preferem vivê-la mais que a real, conforme a pesquisa comportamental com 250 entrevistados na Universidade de Chicago que elegeram o Facebook e o Twitter mais tentadores do que sexo e cigarros (p. 30).

$\mathrm{Na}$ introdução as histórias dos personagens fictícios começam a ser contadas, por exemplo, a da Paula, "a Garota-de-Programa-com-uma-Câmera". Os autores apresentam as características e os equipamentos de tecnologia (iPod e iPhone 5) que a personagem utilizará durante seu conto. Ao narrar o trajeto da personagem para sua casa, mencionam como é intuitiva a ação de elevar o smartphone na altura dos olhos e registrar as coisas que ela acha interessante com a "moniteleobjetiva do seu iPhone 5". Depois de admirar as imagens captadas, ela vai postá-las no Instagram (p. 21). Paula, aos 23 anos, além de gostar de ler mangás (histórias em quadrinhos japonesas), quer ser historiadora, e quem sabe fazer mestrado na Universidade de São Paulo (USP), na área de História do Japão Medieval. A personagem é uma tecnogueixa, quer dizer, ela tem um canal fechado no YouTube pelo qual posta ensaios sensuais, "dali para um programa é um pulo". A história 
da personagem vai ser retomada no Capítulo 3; no Capítulo 4 ela encontra outro personagem, o "Professor Rizomático", e o desfecho acontece no Capítulo 6. Iniciemos agora a compreensão das estruturas, assuntos e ideias apresentadas em cada capítulo.

No primeiro capítulo, os autores descrevem como a sociedade pós-moderna depende profundamente da energia elétrica e da conectividade. É inserido nesta parte o conceito de tempo granular, "o tempo das telas e suas superfícies fluídas de um tempo" Facebook, quando a vida real é postada nas redes sociais por meio de mensagens e fotografias, podendo ser acessadas a qualquer momento, tornando a experiência individual uma ação coletiva.

O segundo capítulo faz referência a uma cidade que "materializa características oriundas da relação entre técnica, espaço e tempo". Menciona como é percebido o tempo e o espaço por pesquisadores como Zygmont Bauman, Nízia Vilaça, Milton Santos, Júlio Cortázar, Pierre Levy, que ajudam a conceituar a pós-modernidade, o não lugar, a mediação e como desejamos ser observados neste tempo ciclope "pois não conseguimos muitas vezes enxergar e compartilhar ao mesmo tempo" (p. 55).

O terceiro capítulo mostra como a invenção de Gutenberg e os sistemas postais revolucionaram as redes sociais. Descreve como a nova tecnologia é rapidamente apropriada pelas pessoas que as valorizam e estimam, e cita a constatação de McLuhan, de que "o meio é a mensagem" e de que os sujeitos escapam para outra ordem de experiência com facilidade.

Assim como Bauman, os autores acreditam que a "linha tênue que separa o real do virtual, o público e o privado está cada vez mais invisível na internet das coisas que vivenciamos diariamente" (p. 64). Eles apresentam que já foram comercializados mais de 6,3 bilhões de celulares, quase a mesma quantidade da população mundial. Nesta realidade percebe-se que os aplicativos e o acesso à internet por meio desses aparelhos contribuem para a dependência dessas novas tecnologias. O nome dado a este tipo de patologia é "nomofobia".

Aqui novamente há menção à personagem Paula. Um cliente desta personagem aproveita que ela cochilou e tira fotos dela nua. Ela acorda e percebe o que está acontecendo, luta com o rapaz e atira o celular dele na parede. Esta atitude foi por medo dos seus familiares e amigos descobrirem que ela é uma garota de programa. "Depois da divulgação de fotos íntimas da Carolina Dieckmann na web nesta semana, parece que virou moda", diz ela para uma seguidora de seu blog.

O quarto capítulo começa com dados estatísticos sobre a navegação dos adolescentes nas redes sociais digitais, bem como seu comportamento e narrativa nesses meios. Cita a relação desses indivíduos com a exposição do privado na internet como um tempo 
Big Brother e ressalta que "não existe lugar mais oportuno para você conhecer seu filho adolescente do que analisar o que ele posta nas redes sociais" (p. 88).

Quanto à história da "Garota-de-Programa-com-uma-Câmera", ela se encontra no corredor da faculdade com seu professor, Pita, "o Rizomático", fala sobre o cotidiano, tira uma fotografia, mostra para ele, usa um filtro do Instagram para deixar a fotografia mais interessante e posta nessa rede.

Como manter a magia, o brilho nos olhos, o encantamento com o que é novo "numa sociedade mediada por APPs e telas numa vida líquida" (p. 95) é o questionamento do quinto capítulo, em que aborda a relação do mundo digital e o mundo real e a relatividade do tempo e do espaço da modernidade líquida de Bauman. É também ressaltado o fenômeno da solidão em meio a tantos amigos nas redes sociais digitais, relacionamentos que se desfazem com facilidade.

No sexto capítulo tem-se o desfecho das histórias dos personagens fictícios que tentam demonstrar as relações deste tempo líquido, fluido e fugidio.

Nem lá, nem cá é o mantra dos autores deste livro. Gostamos de um moleskini para anotar ideias para um novo livro ou, literalmente, para nos socorrer em momentos de tsunami computacional como quando você perde seu acesso \#google (p. 119).

A conclusão leva o leitor a refletir que, apesar das novas tecnologias de comunicação e informação nos propiciarem rapidez, facilidade e mobilidade para realizar nossa interação com os grupos sociais aos quais pertencemos, elas têm um poder viciante, que acaba por nos privar de experiências reais, fora do ciberespaço. Com o título "Nem lá, nem cá” os autores propõem a busca pelo equilíbrio do mundo real e virtual, para que nós possamos entender e utilizar as facilidades que as novas tecnologias nos proporcionam, sem nos esquecer de outras formas de relacionamento com pessoas, espaços e tempos. Eles finalizam com dicas bem-humoradas para que o leitor exercite o equilíbrio da presença virtual e real, como, "Dê mais abraços do que curtidas. Este termômetro é perfeito".

No tempo das telas reúne diversas ideias e conceitos sobre os aparelhos tecnológicos, como televisão, computadores, celulares, tablets etc., e como suas telas contribuem para a transformação do comportamento das pessoas principalmente por causa das redes sociais digitais. Utilizando-se de licença poética ao exemplificar o comportamento do indivíduo nas relações na pós-modernidade por meio de personagens estereotipados da nossa atualidade, demonstra de forma superficial situações que poderiam acontecer no cotidiano de São Paulo, deixando a leitura fluida e agradável no estilo de "romance teen". Em princípio, esta licença poética pode causar estranheza por se distanciar dos padrões 
encontrados em produções científicas e levantar o questionamento da utilidade do livro para o mundo acadêmico. Contrapondo-se à arte, este livro apresenta teorias da comunicação, que versam sobre linguística, linguagem, mídias, tempo, espaço, comunidade, identidade, ciberespaço, modernidade líquida, redes sociais etc., além de usar como referência autores importantes para a pesquisa em comunicação, como Edgar Morin, Henry Jenkins, Jean Baudrillard, Jesús Martín-Barbero, Lucia Santaella, Marshall McLuhan, Winfred Nöth, Pierre Lévy, Roman Jakobson, Umberto Eco, Zygmount Bauman entre outros. O conteúdo do livro contribui para a pesquisa em comunicação de maneira primária, com ideias preliminares e não profundas sobre o tema das novas tecnologias da comunicação e informação no mundo pós-moderno.

A leitura das ideias de Ferrari e Fernandes pode ser uma boa opção para introduzir o leitor no tema das novas tecnologias e comportamentos da sociedade atual, mas não é suficiente para o aprofundamento e entendimento das questões propostas.

FERRARI, P.; FERNANDES, F. No tempo das telas: reconfigurando a comunicação. São Paulo: Estação das Letras e Cores, 2014. 128p. 
